\title{
Hydrological modelling of paired catchments with competing land uses
}

\author{
$\underline{\text { M. Camporese }}^{a b c}$, J. F. Dean ${ }^{c d}$, P. E. Dresel ${ }^{e}$, J. Webb ${ }^{c d}$, E. Daly ${ }^{\text {ac }}$ \\ ${ }^{a}$ Department of Civil Engineering, Monash University, Clayton, Vic, Australia \\ ${ }^{\mathrm{b}}$ Department of Civil, Environmental and Architectural Engineering, University of Padua, Padua, Italy \\ ${ }^{\mathrm{c}}$ National Centre for Groundwater Research and Training, Flinders University, Adelaide, SA, Australia \\ ${ }^{\mathrm{d}}$ Department of Agricultural Science, La Trobe University, Bundoora, Vic, Australia \\ ${ }^{\mathrm{e}}$ Department of Environment and Primary Industries, Bendigo, Vic, Australia \\ Email: matteo.camporese@monash.edu
}

\begin{abstract}
We report the preliminary results of a modelling study of surface/subsurface water interactions applied to a paired-catchment project that is primarily aimed at quantifying the hydrologic response of catchments with competing land uses. The study focuses on a site in southwestern Victoria, Australia, composed by two adjacent catchments with different agricultural uses (grazing and Eucalyptus globulus (blue gum) plantation), but similar topography, geology and soils. The grazing and plantation catchments have a size of 0.48 and $0.76 \mathrm{~km}^{2}$, respectively, and their monitoring network comprises groundwater observation bores, stream gauges and a rainfall station.

We use the distributed, numerical model CATchment HYdrology (CATHY), which simulates flow in the surface, soil, and aquifer zones as well as the hydrological interactions across the atmosphere-land surfacesubsurface continuum. CATHY combines a three-dimensional equation for subsurface flow in variably saturated porous media with a one-dimensional diffusion wave approximation of the de Saint-Venant equation for surface water dynamics. A particular feature of CATHY controls the switching between atmosphere-controlled and soil-limited evapotranspiration; the switching is regulated by a threshold pressure head $\left(\psi_{\min }\right)$ and is used in this study to investigate CATHY's capability to simulate the impact on water fluxes of different types of vegetation.

Preliminary simulation results of a 1-year period show that the model is capable to reproduce satisfactorily the hydrological regime of both catchments without the need for a detailed multiparameter calibration. In particular, the surface hydrological response is matched satisfactorily by the model simulations, with a reasonably good fit (Nash-Sutcliffe coefficients of 0.63 and 0.52 for the grazing and plantation catchments, respectively) in terms of daily flow hydrographs. Water table levels observed in the bores proved to be more difficult to match, even though the overall groundwater dynamics is well captured by the model.

The use of two different values of $\psi_{\text {min }}$, which control the conversion of potential evaporative demand into actual evapotranspiration, accounts for the impact of the different vegetation covers on the total water budget. The two threshold parameters will be accurately calibrated in the next step of this study by matching the simulated fluxes to measurements of actual evapotranspiration. The model will thus allow accurate quantification and comparison of the catchment scale impacts of different agricultural land uses on surface water and groundwater fluxes.
\end{abstract}

Keywords: Surface/subsurface water interactions, paired catchments, hydrological response, evapotranspiration 


\section{INTRODUCTION}

Modifications of land use represent a major component of the human-induced environmental change that the world is currently facing. Alterations of the hydrologic cycle and large emissions of carbon from land to the atmosphere are attributable to clearing of forested lands for agriculture (Bonan, 2008). Several strategies have been developed and trialled to reduce and mitigate carbon emissions, with plantations emerging as a prominent tool for natural carbon sequestration because of their high annual productivity. However, the complexity of the hydrological and ecological processes initiated by the establishment of new plantations on agricultural land is still poorly understood and likely site dependent (Benyon et al., 2006).

Paired-catchment studies have been widely used to determine the magnitude of water yield changes resulting from variations in land use (e.g., Brown et al., 2013) and, in particular, changes in vegetation. These studies usually involve the use of two catchments located close to each other and with similar characteristics in terms of topography, soils, area, climate and vegetation. After a calibration period, where both catchments are monitored, one of the catchments is subjected to a change in land use, while the other remains as a control. One of the advantages of paired catchment studies is that they remove climate variability through the comparison of two catchments subject to the same climatic conditions under different land uses, allowing the changes in hydrological response to be attributed to changes in vegetation. The most common types of land use change reported in the literature of paired catchments are the following (Brown et al., 2005, and references therein):

1. afforestation, where shorter vegetation (e.g., pasture) is converted to forest;

2. regrowth, where removal of vegetation from a percentage of a catchment is followed by regrowth of the same vegetation type;

3. deforestation, where densely vegetated land is converted to grass or pasture;

4. forest conversion, where one forest type is replaced with another.

The time taken to reach a new equilibrium under permanent land use change varies considerably, with deforestation experiments generally reaching a new equilibrium more quickly than afforestation experiments. The separation of land use impacts from climatic factors is a key problem and can be achieved through the comparison of the two catchments not only for annual and mean annual flux totals, but also for flow regime as depicted by the daily annual flow duration curves.

This study is part of a multi-site, paired-catchment investigation into the impacts of land use and climate change on the quality and quantity of ground and surface water resources in southwestern Victoria, Australia (Dresel et al., 2012). Within this context, the specific objective of the present work is to quantify the effect of different productive, agricultural land uses on the catchment hydrology of one of the sites via integrated hydrological modelling. One of the two catchments investigated is predominantly used as perennial pasture, while the other was planted with blue gums in 2008. The measured hydrological response of the paired catchments is compared with the one simulated by a fully coupled model of surface and subsurface flow, for which the calibration of only two parameters was required. We also discuss the functioning of a specific feature of the model that is capable to reproduce the different evapotranspiration fluxes occurring in the two catchments due to the different land use/vegetation cover.

\section{METHODS}

\subsection{STUDY AREA}

The study area (Figure 1) is located near Mirranatwa, $230 \mathrm{~km}$ west of Melbourne, and consists of a pair of small, adjacent catchments; one catchment is predominantly covered with a recently planted (July 2008) Eucalyptus globulus (Blue Gum) plantation $\left(0.76 \mathrm{~km}^{2}\right)$, the other is a farm, predominantly used as a pasture for sheep $\left(0.48 \mathrm{~km}^{2}\right)$. The area is surrounded on three sides by sandstone ridges of the Grampians Range. Bedrock consists of weathered to consolidated granitic rock. The granite is overlain by up to $7 \mathrm{~m}$ of alluvial/colluvial material (bleached-mottled, eutrophic, brown chromosols, according to the Australian Soil Classification (Isbell, 2002)) along and adjacent to the drainage lines, and the granite itself is well weathered to a depth that shows significant spatial variability but that can be considered, on average, about $10 \mathrm{~m}$ in both the farm and plantation catchments. The topography of the site (hills in the middle of a broad valley, Figure 1) is such that it is reasonable to assume there is no regional groundwater input, and both catchments are local groundwater 

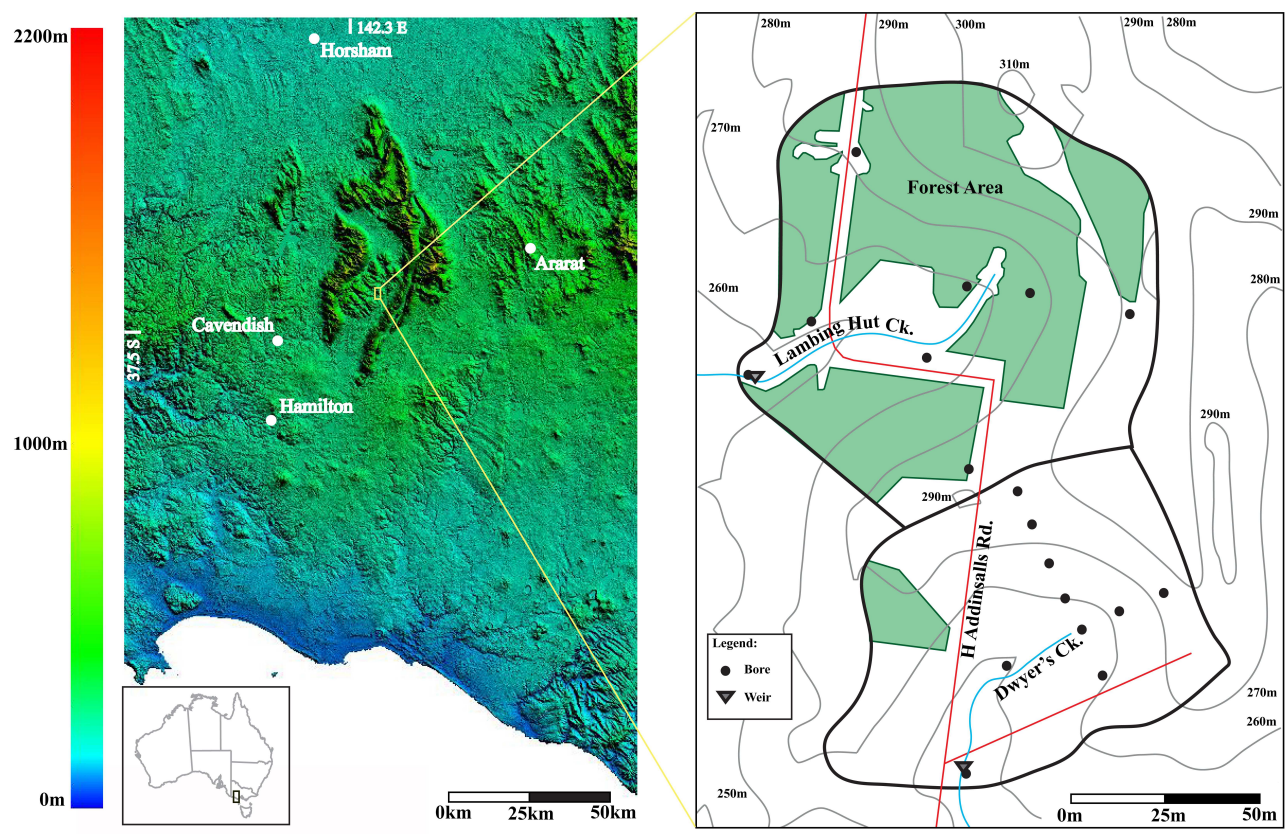

Figure 1. Site location and monitoring network.

systems. Topography in the plantation catchment varies by up to $50 \mathrm{~m}$ vertically, and by $30 \mathrm{~m}$ in the farm catchment, but both catchments have reasonably steep hills which break into a gentle slope down towards the drainage lines (Figure 1). The farm catchment has 13 bores drilled to different depths, and the plantation catchment has 10 bores. Every bore in the plantation catchment is equipped with a groundwater logger, measuring at a minimum 4 hour time interval; 8 bores in the pasture catchment have loggers measuring at the same frequency. Each catchment is equipped at the outlet with a weir, with one bore immediately adjacent to the weir in the plantation and two next to the pasture catchment weir. The bores adjacent to the weirs use pressure transducers measuring water level and electrical conductivity at 30-minute intervals, while the other bores have loggers measuring water level only. At the weirs the surface water level is measured using a standard Vnotch construction, and electrical conductivity is recorded using a logger in the weir pool (Dresel et al., 2012). Note that unfortunately there was no monitoring of the plantation site prior to planting of the trees, so that we can only rely to data collected in the farm for the evaluation of pasture land use. The monitoring network is completed by a full weather station that measures rainfall, humidity, solar radiation, and wind speed and direction. The climate is Mediterranean or maritime/temperate (code $C f b$ in the Köppen classification); the average annual rainfall for the area is $672 \mathrm{~mm}$, while pan evaporation is $1350 \mathrm{~mm}$ annually, exceeding rainfall for the majority of the year, with the exception of the winter months from May through September (data from Bureau of Meteorology, Hamilton, Australia).

\subsection{Integrated hydrological model}

CATHY is a coupled physically-based spatially-distributed model for surface-subsurface flow simulations (Camporese et al., 2010). The model is based on the solution of a one-dimensional diffusion wave approximation of the de Saint-Venant equation for overland and channel routing nested within a solver for the three-dimensional equation for subsurface flow in variably saturated porous media (i.e., Richards equation). The routing scheme derives from the Muskingum-Cunge discretization of the kinematic wave equation based on the matched artificial dispersivity method. Surface runoff is propagated through a 1D drainage network of rivulets and channels automatically extracted by a DEM-based pre-processor and characterized using hydraulic geometry scaling relationships. The distinction between overland and channel flow regimes is made using threshold-type relationships based on, for instance, upstream drainage area criteria. Lakes and other topographic depressions are identified and specially treated as part of the DEM pre-processing procedure. The subsurface solver is based on Galerkin finite elements in space, a weighted finite difference scheme in time, and linearization via Newton or Picard iteration. 
A procedure to switch boundary conditions is used to partition atmospheric potential fluxes (i.e., rainfall and potential evapotranspiration) into actual fluxes across the land surface (i.e., infiltration and actual evapotranspiration) and changes in surface storage (Putti and Paniconi, 2004; Camporese et al., 2010). This procedure regulates the terms in CATHY that couple surface and subsurface waters. The switching procedure distinguishes four possible states for a given surface node: ponded, saturated, unsaturated, and air-dry. The distinction between ponded and saturated is based on a threshold parameter $\left(h_{\min }[\mathrm{m}]\right)$ that represents the minimum water depth before surface routing can occur; this threshold would be zero, for instance, for perfectly smooth surfaces and higher for increasingly rough surfaces. The case of evaporation is considered to be analogous to the threshold behavior that occurs during rainfall when the surface becomes saturated or ponded. When the unsaturated surface soil reaches a moisture deficit threshold, parameterized by its corresponding pressure head level $\left(\psi_{\min }[\mathrm{m}]\right)$, the boundary condition switches from Neumann to Dirichlet, and the evapotranspiration process becomes soil- and/or vegetation-limited. Therefore, $\psi_{\min }$ can be interpreted either as the "air-dry" value for that soil (e.g., Hollinger and Isard, 1994), the switching point representing the advent of stage two evaporation (Salvucci, 1997), or as a proxy for the critical root potential below which the xylem hydraulic conductivity declines as $\psi$ declines. For more details about the algorithm governing the switching procedure, see Putti and Paniconi (2004) and Camporese et al. (2010).

\subsection{Simulation setup}

Starting from a $20 \mathrm{~m} \times 20 \mathrm{~m}$ resolution DEM, the two catchment 3D subsurface grids were constructed by subdividing each DEM cell into two triangles and then projecting these 2D surface meshes vertically for the total depth of the simulation domain. Based on bore logs collected in the field, soil depth for both farm and plantation grids was assigned a value of $10 \mathrm{~m}$, for a total of 16 vertical discretization layers. Starting from the thinnest mesh stratum $(0.05 \mathrm{~m})$ at the surface, needed to accurately resolve rainfall-runoff-infiltration partitioning and to better capture the interactions between surface water and groundwater, the layers progressively coarsen with depth, to a maximum thickness of $2.0 \mathrm{~m}$. The resulting 3D grid contains 22066 nodes and 116160 tetrahedral elements for the pasture and 34153 nodes and 182880 elements for the plantation.

We simulated the period from 16 February 2011 to 15 February 2012. The atmospheric boundary conditions consisted of rainfall as measured by the rain gauge and potential evapotranspiration estimated by means of the Hargreaves-Samani formula (Hargreaves and Samani, 1982) as a function of temperature data. Actual evapotranspiration was then calculated by the model depending on the parameter $\psi_{\text {min }}$, as discussed in the previous section. No-flow conditions were assigned to the base of the soil domain as well as to all the lateral boundaries. The initial conditions were generated by running spin-up periods for the previous two years, using measured rainfall rates and estimated evapotranspiration fluxes. Our numerical experiments showed that for both catchments this duration of spin-up periods is sufficient to obtain a state that is physically consistent and essentially unaffected by the conditions assigned at the beginning of the spin-up. The pressure head and surface discharge distributions at the end of the spin-up were then used as initial conditions for the considered simulations.

A detailed multiparameter calibration was not carried out for this study, as it was possible to estimate all the soil parameters needed by the model from information collected in the field and/or from the literature. Several soil samples were collected at various depths and bores, and taken to the laboratory for an accurate grain size analysis. Grain size distributions were then used to estimate saturated hydraulic conductivity, porosity, and van Genuchten (van Genuchten, 1980) retention curve parameters by means of the Rosetta model (Schaap et al., 2001). Hydraulic conductivity at saturation, $K[\mathrm{~m} / \mathrm{s}]$, was found to be decreasing with depth $z[\mathrm{~m}]$ according to a power law $\left(K=1.01 \times 10^{-5} z^{-0.27}\right)$, with very little horizontal spatial variability, while porosity was approximately homogeneous in space and averaged 0.40 . Retention curve parameters displayed more variability, with average values of residual water content $\theta_{r}$ and van Genuchten fitting parameters $\alpha$ and $n$ equal to $0.03,1.85 \mathrm{~m}^{-1}$ and 1.52 , respectively. Simulation results were found to be insensitive to the specific storage; therefore, a spatially uniform value of $1.0 \times 10^{-3} \mathrm{~m}^{-1}$ was assigned to both catchments, consistent with values found in the literature. The surface routing coefficients were also assigned on the basis of literature data and were assumed to be spatially variable according to the scaling relationships reported in Camporese et al. (2010). In the plantation, due to the arrangement of the tree furrows, which run along the slope of the catchment, thereby facilitating the surface flow toward the outlet, Manning resistance coefficients were assigned two times smaller than in the farm $\left(0.05 \mathrm{vs} 0.1 \mathrm{~s} \mathrm{~m}^{-1 / 3}\right.$, for a flow discharge equal to unity and a draining area equal to total catchment area). The only parameters that needed adjustment in order to achieve a satisfactory match between simulated and observed states were $h_{\min }$ and $\psi_{\min }$. A minimum 
ponding threshold of $0.001 \mathrm{~m}$ provided a good fit for both the farm and plantation catchments and reasonably represents the actual roughness of the soil surface in the study site. Finally, we assigned values of $-10.0 \mathrm{~m}$ $(-0.1 \mathrm{MPa})$ and $-50.0 \mathrm{~m}(-0.5 \mathrm{MPa})$ to the evaporative threshold parameter $\psi_{\min }$ in the farm and plantation catchments, respectively, to reflect the properties of the different vegetation covers.

\section{RESULTS AND DISCUSSION}

Figure 2 shows the comparison between observed and modelled streamflow in both catchments. With minimum calibration $\left(h_{\min }\right.$ and $\psi_{\min }$ only), the model is capable to reproduce reasonably well the magnitude and timing of daily streamflow, with Nash-Sutcliffe coefficients for the farm and plantation of 0.63 and 0.52 , respectively. This is a satisfactory result, especially if we consider that streamflow represents only $3 \%$ of the total annual precipitation in both catchments $(\approx 20 \mathrm{~mm} /$ year vs $\approx 601.8 \mathrm{~mm} /$ year $)$. Flow seasonality in particular, typical of ephemeral streams, is well captured by the model; the first peaks of the wet season are missed by the simulations, especially in the farm, probably due to uncertainties in the initial conditions. The main differences between the hydrological regime of the plantation compared to the farm are that i) peak flows are usually higher and ii) low flows, although smaller, are more persistent. The former is due probably not only to the aforementioned arrangement of the tree furrows, but also to the fact that the plantation catchment has a distribution of plan curvature values with a more negative tail compared to the farm (not shown). Negative values of plan curvature correspond to topographic convergence and hence the tendency of water to converge as it flows across the land. More persistent low flows in the plantation can be explained by another metric of the catchment surface: the topography index $(T P I)$ (Beven and Kirkby, 1979), defined as $\ln (a / \tan \beta)$, where $a$ is the upslope area per unit contour length and $\tan \beta$ is the slope gradient. High values of TPI reflect the drainage of large upslope areas and/or low gravitational gradients, and thus a greater potential for the development of saturation. The shape of the topography index distribution (not shown) is very similar in the two catchments, with slightly larger values in the plantation, due to larger contributing areas that compensate for smaller slopes. Near the outlet, the plantation has a TPI very similar to that of the farm outlet, but with a larger drainage area, which means that the slope is smaller and this could explain why the lowest part of the catchment in the plantation is more prone to saturation and hence to sustain baseflow for longer. Contrary to what expected and found in other paired catchment studies (Brown et al., 2005), mean annual runoff in the plantation is not smaller than in the farm (20.6 mm/year vs $20.5 \mathrm{~mm} /$ year in the 2-year period 2011-2012). However, this could be a temporary effect due to the relatively young age of the trees; monitoring activities are still ongoing to confirm whether annual streamflow in the plantation is stable or it is gradually reducing due to the vegetation growth. Estimated larger evapotranspiration in the plantation $(636 \mathrm{~mm} / \mathrm{year})$ than in the farm $(583 \mathrm{~mm} /$ year $)$ is compensated by a change in groundwater storage that is much greater in the plantation $(-55$ $\mathrm{mm} /$ year vs $-5 \mathrm{~mm} /$ year).

A reasonable match between the observations and the simulations is also achieved for the water table levels in the shallow bores of both catchments (not shown). Although the absolute values of the measured water table are more difficult to fit than the streamflow values, the groundwater dynamics is generally well captured by the model.

Figure 3 illustrates how the estimated potential evapotranspiration, used to force to the model, is converted to actual evapotranspiration. In the farm, the less negative $\psi_{\min }(-0.1 \mathrm{MPa})$ does not allow the soil to dry too much, simulating a grass cover with limited transpiration demand; as a result, the cumulative actual evapotranspiration flux at the end of the simulated period is $43 \%$ of the total potential demand. In the plantation, where the trees use more water to sustain their life cycle, a more negative value of $\psi_{\min }(-0.5 \mathrm{MPa})$ implies that the soil is allowed to yield more water in response to the potential evapotranspiration demand, so that the cumulative total evapotranspiration flux at the end of the simulation is $4 \%$ greater than in the farm. This small difference, compared to the large $\psi_{\min }$ ratio between the plantation and the farm, highlights the strong nonlinearity of the process handled by the simulation model.

\section{CONCLUSIONS}

An integrated hydrological model for the simulation of coupled surface/subsurface flow was applied to a paired catchment experiment in Victoria, Australia. The model is capable to reproduce the hydrological regime of two catchments subjected to different land uses (pasture and blue gum plantation) with minimum calibration; only two parameters were preliminarly tuned, while all the remaining parameters were assigned based on field or literature data. It is also demonstrated how a boundary condition-switching procedure based on a physicallybased pressure head threshold is suitable to reproduce the control exerted on the catchment water fluxes by the 
M. Camporese et al., Hydrological modelling of paired catchments with competing land uses
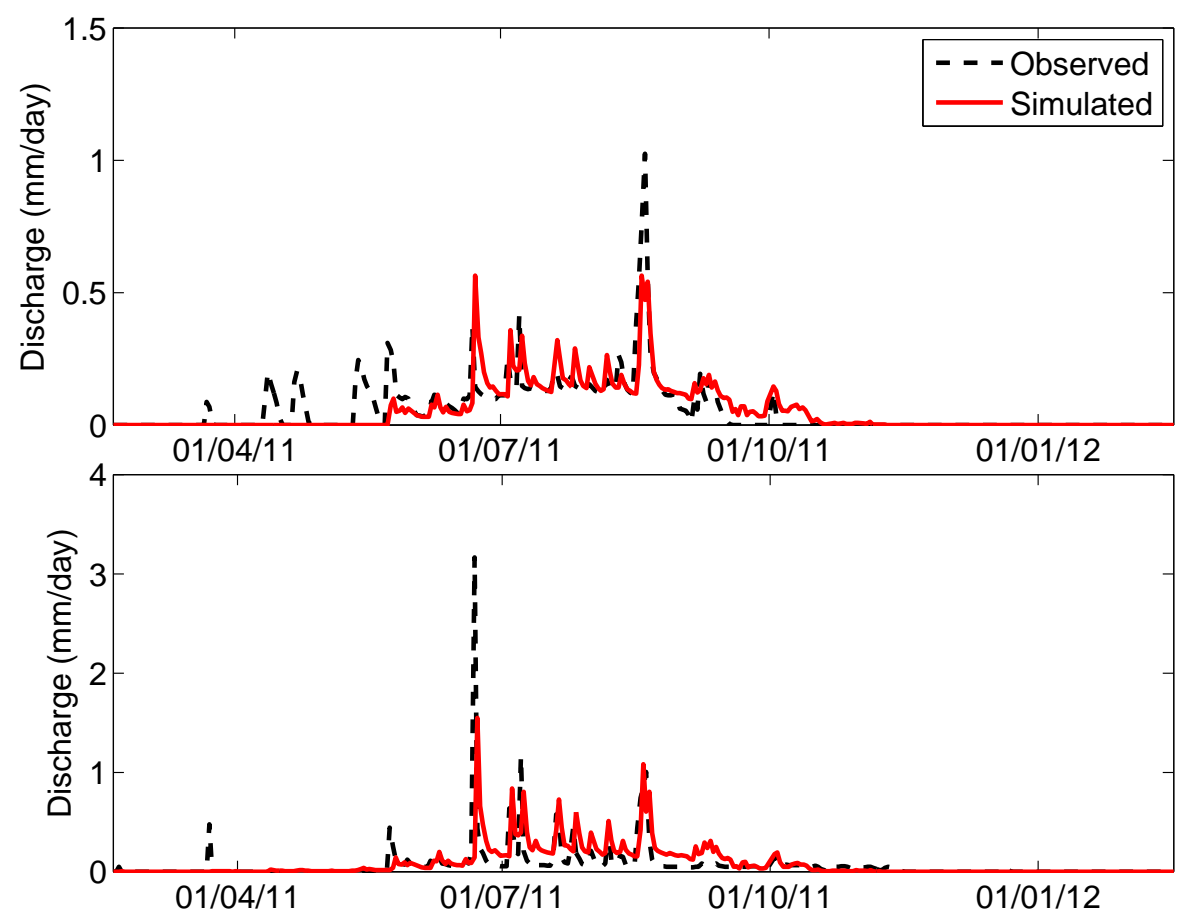

Figure 2. Observed and modelled daily streamflow in the farm (top) and plantation (bottom) catchments.

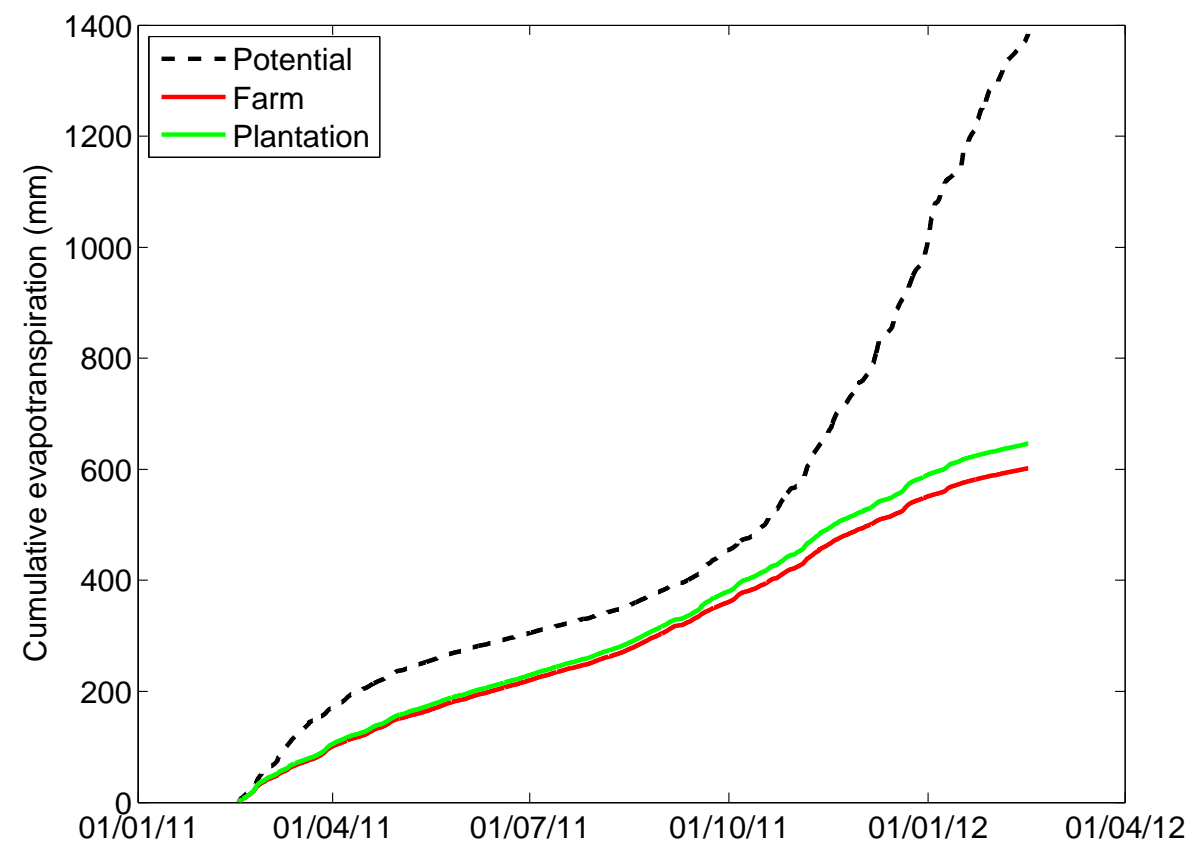

Figure 3. Comparison between cumulative potential evapotranspiration and actual evapotranspiration as simulated by the model in the farm and plantation catchments. 
predominant vegetation cover.

The results shown in this paper refer to the preliminary calibration of the model. Future work will involve a refinement of the calibration and the validation phase, where the parameter $\psi_{\min }$ will be further corrected in order to optimize the match between simulated and observed actual evapotranspiration fluxes, measured in the period March 2012-February 2013 by an eddy-covariance flux tower in the grazing catchment and by sap flow probes in the plantation catchment.

\section{ACKnowledgements}

This work has been funded by the Australian Research Council and the National Water Commission through Program 4 (Groundwater-Vegetation-Atmosphere Interactions) of the National Centre for Groundwater Research and Training. Logistic support by the staff of the Victoria Department of Environment and Primary Industry staff is also gratefully acknowledged. Finally, we thank the landowners (Marcia Field and Macquarie Bank Foundation) for granting us access to their properties.

\section{REFERENCES}

Benyon, R. G., S. Theiveyanathan, and T. M. Doody (2006). Impacts of tree plantations on groundwater in south-eastern Australia. Australian Journal of Botany 54(2), 181-192.

Beven, K. J. and M. J. Kirkby (1979). A physically based, variable contributing area model of basin hydrology. Hydrological Sciences Bulletin 24(1), 43-69.

Bonan, G. B. (2008). Forests and climate change: Forcings, feedbacks, and the climate benefits of forests. Science 320(5882), 1444-1449.

Brown, A. E., A. W. Western, T. A. McMahon, and L. Zhang (2013). Impact of forest cover changes on annual streamflow and flow duration curves. Journal of Hydrology 483, 39-50.

Brown, A. E., L. Zhang, T. A. McMahon, A. Western, and R. A. Vertessy (2005). A review of paired catchment studies for determining changes in water yield resulting from alterations in vegetation. Journal of Hydrology 310, 28-61.

Camporese, M., C. Paniconi, M. Putti, and S. Orlandini (2010). Surface-subsurface flow modeling with pathbased runoff routing, boundary condition-based coupling, and assimilation of multisource observation data. Water Resources Research 46, W02512.

Dresel, P. E., P. Hekmeijer, J. F. Dean, W. Harvey, J. A. Webb, and P. Cook (2012). Use of laser-scan technology to analyse topography and flow in a weir pool. Hydrology and Earth System Sciences 16(8), 2703-2708.

Hargreaves, G. H. and Z. A. Samani (1982). Estimating potential evapo-transpiration. Journal of the Irrigation and Drainage Division-ASCE 108(3), 225-230.

Hollinger, S. E. and S. A. Isard (1994). A soil moisture climatology of Illinois. Journal of Climate 7(5), 822-833.

Isbell, R. (2002). The Australian Soil Classification. Australian Soil and Land Survey Handbooks Series 4. CSIRO Publishing.

Putti, M. and C. Paniconi (2004). Time step and stability control for a coupled model of surface and subsurface flow. In C. T. Miller, M. W. Farthing, W. G. Gray, and G. F. Pinder (Eds.), Computational Methods in Water Resources, Vols 1 and 2, Volume 55 of DEVELOPMENTS IN WATER SCIENCE, pp. 1391-1402.

Salvucci, G. D. (1997). Soil and moisture independent estimation of stage-two evaporation from potential evaporation and albedo or surface temperature. Water Resources Research 33(1), 111-122.

Schaap, M. G., F. J. Leij, and M. T. van Genuchten (2001). Rosetta: a computer program for estimating soil hydraulic parameters with hierarchical pedotransfer functions. Journal of Hydrology 251(3-4), 163-176.

van Genuchten, M. T. (1980). A closed-form equation for predicting the hydraulic conductivity of unsaturated soils. Soil Science Society of America Journal 44, 892-898. 